\title{
Adequação lexical como demonstrativo de competência comunicativa escrita no gênero redação
}

\author{
Lexical adequacy as a demonstrative of written communicative \\ competence in the genre essay \\ Karen Pereira Fernandes de Souza \\ Universidade Federal do Rio de Janeiro \\ Welton Pereira e Silva \\ Universidade Federal do Rio de Janeiro \\ DOI: https://doi.org/10.5902/2176148532578
}

RESUMO: partindo da Linguística de Texto, da Análise do Discurso e de estudos sobre Normas linguísticas, analisam-se quatro redações de vestibular visando mostrar os problemas característicos dos candidatos com notas baixas e os bons resultados daqueles que adequaram seu léxico para mais bem expressarem suas opiniões. Faz-se uma reflexão sobre como os professores poderiam atuar em sala de aula, objetivando a melhoria da escrita. Notou-se que as escolhas lexicais relativas a referentes vagos ou ambíguos, bem como a utilização de construções semânticas cristalizadas, prejudicam a compreensão textual, o que culmina na baixa pontuação. Ao final das análises, propõe-se alguns exercícios.

Palavras-chaves: Ensino da escrita. Adequação lexical. Gênero redação. Competência comunicativa.

ABSTRACT: starting from Textual Linguistics, Discourse Analysis and studies on linguistic Norms, four essays are analyzed to show the problems of candidates with low grades and the good results of those who have improved their lexicon to better express their opinions. It is made an analysis of how the teacher can act in class, aiming at improving writing. It was notice that the lexical choices related to vague referents or ambiguous, as well as the use of the cristalized semantic constructions, prejudice the textual understanding, and this conduce to the low score. At the end of the analyzes, some exercises are proposed. Keywords: Teaching of writing. Lexical adequacy. Genre essay. Communicative competence. 


\section{Introdução}

Uma das principais preocupações dos professores de língua portuguesa em relação aos alunos que prestam o Exame Nacional do Ensino Médio (ENEM) e os demais exames de acesso ao nível superior de ensino (Vestibular) diz respeito à forma como os candidatos devem adequar seu

Karen Pereira

Fernandes de

Souza

Welton Pereira

e Silva

184 léxico de modo a mais bem expressarem suas opiniões e seus conhecimentos, objetivando uma boa nota no concurso.

Apesar de essa ser uma preocupação legítima e atual, nem sempre o conteúdo acerca de como fazer apropriadamente a adequação lexical em textos escritos é abordado de forma eficiente nas aulas de redação. Tal fato se dá por não encontrarmos facilmente materiais que discutam a maneira como essa questão deve ser tratada.

Dessa forma, no presente artigo, trazemos algumas reflexões a respeito da importância de os estudantes ficarem atentos à escolha lexical no momento da construção textual que visa, principalmente, ao ingresso no ensino superior. Faremos uma análise de quatro redações do Vestibular da Universidade Federal do Rio de Janeiro, do ano de 2009, seguindo o critério de avaliação do exame para a competência "Norma", pertencentes à amostra Corpus Rio Acadêmico Escolar. A partir da análise realizada, procuraremos apresentar alguns exercícios que auxiliem a prática do professor ao trabalhar adequação vocabular em redações.

Para que nossas reflexões se tornem profícuas, na primeira parte do trabalho, Escolha lexical sob um ponto de vista discursivo, apresentamos a visão da Linguística de Texto e da Análise do Discurso a respeito da questão da escolha e da adequação lexical em diferentes gêneros textuais visando a atingir determinadas finalidades na interação sociocomunicativa. Dedicamos a segunda parte para falar sobre as Relações entre norma, adequação e competência comunicativa. Nessa parte, trataremos das questões sobre as diferentes normas linguísticas existentes e de como a consciência e o domínio dessa pluralidade e do repertório lexical adequado às situações de comunicação são importantes para um efetivo desenvolvimento da competência comunicativa dos alunos. Também mostraremos a organização do Corpus $e$ orientações para a redação do Vestibular/UFRJ do ano de 2009, material de análise deste trabalho.

Na terceira parte, fazemos uma reflexão sobre quatro redações de Vestibular em Exame das redações e propostas de exercícios a partir de excertos reais, em que procuramos demonstrar como a adequação le- 
xical pode se tornar uma excelente aliada para que o estudante não contrarie o seu discurso. A seguir, apresentamos algumas propostas práticas para tratar da seleção lexical em sala de aula juntamente com algumas sugestões de resposta. Posteriormente, encerramos o artigo com as Considerações Finais.

\section{Adequação \\ lexical como \\ demonstrativo \\ de competência \\ comunicativa \\ escrita no \\ gênero redação}

\footnotetext{
refere os textos materializados em situações comunicativas correntes. Os gêneros textuais são os textos que encontramos em nossa vida diária e que apresentam padrões sociocomunicativos característicos definidos por composições funcionais, objetivos enunciativos e estilos concretamente realizados na integração de forças históricas, sociais, institucionais e técnicas (MARCUSCHI, 2017, p. 155).
}

Como entidades empíricas dotadas de objetivos particulares, os gêneros servem a determinadas finalidades sociais. A depender da finalidade, do contexto interacional, dos participantes envolvidos na troca comunicativa, fazemos uso de um registro mais ou menos formal do código linguístico. Assim, não nos dirigimos a um colega de trabalho em um encontro no bar depois do expediente do mesmo modo como nos reportamos ao médico em uma consulta no ambulatório. A noção de "registro" nos remete a Câmara Jr. (1970), que nos explica que "registro" é quando o indivíduo é mais formal ou menos formal a depender da situação em que se encontra, portanto, faz parte da competência comunicativa do sujeito. Esclarecendo melhor essa e outras nomenclaturas que se relacionam, Charaudeau (1999) nos esclarece que: 
Karen Pereira

Fernandes de

Souza

Welton Pereira

e Silva

186
Quando utilizamos os termos de <<competência comunicativa $>>$, <<competência dialógica >> (no sentido Bakhtiniano), trata-se de assinalar o que acaba de ser dito, ou seja, que a competência de produção/interpretação ultrapassa o simples conhecimento das palavras e de suas regras de combinação e requer um saber bem mais global, que compreende outros elementos da interação social e que, não obstante, fazem parte do processo de enunciação (CHARAUDEAU, 1999, p. 30).

Essa competência comunicativa está relacionada ao contrato de comunicação, noção que diz respeito ao conjunto de regras que rege a forma como devemos nos comportar discursivamente em uma dada situação de comunicação. Para Charaudeau (2005), os participantes de uma interação se perguntam a todo instante "estamos aqui para fazer o quê?", tal pergunta diz respeito à finalidade daquela interação. Da mesma forma, esses participantes precisam ter em mente que o status social, a identidade que o locutor assume naquele momento e a identidade de seu interlocutor também interferem no contrato. Assim, recorrendo ao exemplo de interação dado acima, em um dado momento, a identidade de "colega de trabalho" emerge enquanto que, no outro, é a identidade de "paciente" que se torna a mais importante em um consultório médico.

Deste modo, os sentidos de um texto só podem ser adequadamente entendidos quando consideramos o contexto sócio-histórico de sua produção. Ou seja, entendemos que os sentidos não são dados a priori, mas são constituídos através do uso ancorado em uma prática social. O sentido de um termo é, portanto, apenas potencial. Esse ponto de vista atravessa várias disciplinas linguísticas desde a Virada Pragmática (ocorrida na década de sessenta, a partir da qual muitos contributos foram aderidos às ciências da linguagem) até o âmbito da Linguística de Texto e das várias vertentes da Análise do Discurso.

Devido a tudo isso, é facilmente perceptível a importância dada à escolha lexical, à adequação da língua escrita feita pelos falantes a depender da situação de comunicação na qual estão inseridos. Essa adequação lexical natural depende da competência comunicativa do sujeito e, por isso, precisa ser trabalhada em sala de aula para que o estudante tenha cada vez mais noções acerca da importância de um vocábulo ser preferível em relação a outro em um determinado contexto. Na verda- 
de, a depender das escolhas lexicais realizadas, é possível até mesmo entrever a opinião e certos valores axiológicos defendidos pelo enunciador, pois, como bem explica Possenti:

[...] se digo que os sem-terra ocuparam uma fazenda, rejeito que eles a tenham invadido. Ou seja, um certo discurso e, consequenAdequação lexical como temente, um certo sujeito rejeita invadir (dizendo ocupar). Outro demonstrativo rejeita ocupar (dizendo invadir). Não se trata de uma seleção pade competência radigmática, em termos de língua, mas de assumir uma posição discursiva (POSSENTI, 2004, p. 377. Grifos no original).

comunicativa escrita no gênero redação

Assim, a escolha lexical de um termo em vez de outro denota um ponto de vista sobre o mundo, apresentando valor argumentativo. Com isso, conforme ensina Possenti (2004), nem sempre a escolha ou adequação se fundamenta, simplesmente, pela seleção paradigmática. Notamos, portanto, que vários pesquisadores em diversas disciplinas linguísticas possuem preocupações de investigação concernentes à escolha lexical em determinados discursos. Dessa forma, por ser uma questão importante para as ciências da linguagem, faz-se necessário observar e refletir acerca da escolha ou adequação lexical no âmbito do ensino escolar, nomeadamente em um gênero amplamente trabalhado nesse espaço: a redação de vestibular.

Pensando na importância de o professor trabalhar com seus alunos a adequação lexical para a boa produção e interpretação textual, Simões e Rei (2015) nos dizem:

Para evitar situações em que o sujeito lê uma coisa e entende outra, ou quer dizer uma coisa e acaba dizendo outra, cumpre trazer o trabalho com o léxico para o centro das práticas pedagógicas das línguas em geral e das aulas de língua portuguesa, em especial (p. 45).

E ainda:

No plano funcional, deve-se chamar a atenção do falante para a importância da escolha das palavras e expressões na formulação dos enunciados com que irá comunicar-se. Dependendo da seleção realizada, sua comunicação poderá ser eficiente ou não. 


\begin{abstract}
Ademais, de suas opções vocabulares também podem resultar situações agradáveis e desagradáveis, uma vez que na interação mobilizam-se afetos, estados de espírito do interlocutor; logo, se a escolha não for acertada, os resultados da interação poderão ser desastrosos (p. 58).
\end{abstract}

Karen Pereira

Fernandes de

Souza

Welton Pereira

e Silva

188

Assim, é de suma importância um trabalho com os alunos do ensino básico que busque suscitar o entendimento de que o domínio de um adequado repertório lexical é condição sine qua non para o sucesso na prática da redação. Além disso, nos anos finais do Ensino Médio, quando os estudantes passam a se preocupar com a obrigatoriedade de obter um bom resultado em exames que visam ao ingresso no nível superior, essa atenção deve ser redobrada por parte dos docentes e discentes.

\title{
2. Relações entre norma, adequação e competência comunicativa
}

Além do que foi exposto no item 1, devemos também considerar a distinção entre normas de uso, norma padrão e norma gramatical, já que "Norma" é uma das competências cobradas ao serem avaliadas as redações de vestibular (material de análise deste trabalho), situação essa em que o candidato deve mostrar que a domina satisfatoriamente. A polissemia do termo "norma" é bastante complexa, uma vez que há mistura de diversos conceitos de normas em uma única abordagem: norma padrão. Desta forma, levando em conta a tripartição de sistema-norma-fala lançada por Coseriu (1987), "Norma” será conceituada da seguinte maneira: é um modelo, é um padrão de fala seguido por um determinado grupo de falantes de uma comunidade linguística.

A partir deste conceito, não podemos mais pensar na existência de apenas um modelo, de uma única norma a ser seguida por todos os falantes de uma língua. Pelo contrário, existe uma pluralidade de normas/ variedades segundo os níveis sócio-econômico-culturais e os contextos sociocomunicativos. Isso acontece porque, segundo Faraco (2008), a norma está hierarquizada em dois grandes grupos: (a) norma padrão (ou subjetiva), baseada no modelo lusitano de escrita; (b) normas de uso (ou objetiva), que se trata de um conjunto de variedades efetivamente praticado pelos usuários de uma língua. Este último grupo, por sua vez, divide-se em dois subgrupos: (b.1) normas cultas (de uso), correspondendo aos usos linguísticos normais/correntes/usuais dos falantes mais escolarizados 
em situações mais monitoradas (de fala/escrita); (b.2) normas populares (de uso), correspondendo aos usos linguísticos normais/correntes/usuais dos falantes menos escolarizados (na fala/escrita).

Há, ainda, a norma gramatical que veio para "flexibilizar os juízos normativos, quebrando, pelo menos em parte, a rigidez da tradição excessivamente conservadora" (FARACO, 2008, p. 81). Esta pode ser encontrada nos nossos melhores dicionários e gramáticas de Língua Portuguesa, a chamada Gramática Tradicional, como uma orientação para uma escrita ideal mais próxima da Norma culta.

Frente à quantidade de fatores ${ }^{1}$ linguísticos e extralinguísticos que agem sobre a língua, fica evidente que não poderia haver apenas uma única norma para todos os falantes, mas sim uma variedade de normas de acordo com seus grupos sociais, destoando verticalmente na Adequação lexical como demonstrativo de competência comunicativa escrita no gênero redação pirâmide social e horizontalmente no espaço geográfico. Por isso, podemos dizer a "norma culta carioca", a "norma culta paulista", a "norma popular da favela", a "norma popular do subúrbio" etc.

Então, uma pergunta se faz necessária: e o que a norma tem a ver com a adequação lexical e a competência comunicativa? A resposta será “tudo", porque, segundo Travaglia (1997, p. 66), a Escola, tomada de preconceitos, "tende a esconder a relação entre língua e grupos sociais, sobretudo entre norma culta e padrão e classe social privilegiada". Consequentemente, vigora a forma "correta" frente à forma "errada" empregada pelos alunos, porque a linha normativa escolhida é a norma padrão, com a justificativa do "bem falar e escrever" e, por consequência, estigmatiza os falares não escolarizados. Entretanto, com a pluralidade de normas linguísticas existentes e pelos diversos fatores internos e externos que influenciam a língua, a norma padrão não deveria ser a única norma aprendida na Escola.

Com as pesquisas sociolinguísticas efervescendo no final do século XX e início do século XXI, houve uma grande pressão na Sociedade e nas Escolas por parte dos linguistas para reverter esse quadro conservador, sobretudo, com a implantação do ENEM como forma de ingresso para grande parte das Universidades Públicas do Brasil. Os professores pesquisadores reivindicavam a inserção do estudo de variação linguística em sala de aula (já prevista nos Parâmetros Curriculares Nacionais

1 Segundo Câmara Jr (1970), esses fatores seriam Variação Diatópica, Variação Diastrática, Variação Diafásica e Registro. 


\section{Karen Pereira \\ Fernandes de \\ Souza \\ Welton Pereira \\ e Silva \\ 190 é ampliar a capacidade do aluno em permear com desenvoltura por di- versos contextos de situações interacionais (fala/escrita), de modo que o aprendiz possa ter a capacidade de perceber e ter:

\footnotetext{
o domínio da expressão oral e escrita em situações de uso público da linguagem, levando em conta a situação de produção social e material do texto (lugar social do locutor em relação ao(s) destinatário(s); destinatário(s) e seu lugar social; finalidade ou intenção do autor; tempo e lugar; material da produção e do suporte) e selecionar, a partir disso, os gêneros adequados para a produção do texto, operando sobre as dimensões pragmática, semântica e gramatical (BRASIL, 1998, p. 49).
}

- PCNs) para que, desse modo, os alunos pudessem perceber a necessidade de determinados usos em determinadas situações sociocomunicativas, o que impacta diretamente na escolha lexical e na competência comunicativa dos estudantes.

Segundo os PCNs de língua portuguesa, um dos papéis da Escola

Assim, conseguiríamos substituir de vez a ideia do uso certo/ errado pela ideia do uso adequado/não adequado de acordo com o contexto/situação de comunicação. O estudo de língua portuguesa, nomeadamente da escrita, em sala de aula, deve ir além do ensino de regras gramaticais. Nesse sentido, é de extrema valia os exercícios de adequação vocabular porque todo ato discursivo (fala/escrita) requer um contrato comunicativo, ou seja, um pacto de comum acordo entre os participantes da comunicação que aceitam de antemão as regras do jogo comunicativo, logicamente, para não haver prejuízo/falha na comunicação. Sendo assim, à maneira de um contrato jurídico, além do gênero, dos tipos textuais, dos operadores lógicos, a norma linguística seria equivalente a um dos "artigos" desse contrato que não pode ser infringido e a escolha lexical seria equivalente a um dos "parágrafos" do artigo referente à norma.

As questões que unem a norma linguística e a escolha lexical estão intimamente ligadas à competência comunicativa, porque é a competência comunicativa que está sendo avaliada no corpus utilizado neste artigo (análise de quatro redações de vestibular). Em outras palavras, para que o participante receba uma boa nota, ele deverá mostrar ao avaliador que tem competência comunicativa, que ele sabe se expressar 
na modalidade escrita da língua portuguesa, com um repertório lexical adequado à norma linguística adotada naquele gênero específico: a norma culta escrita. Vejamos um pouco mais sobre as exigências linguísticas e estruturais do gênero redação de vestibular na próxima seção.

\subsection{Gênero redação de vestibular}

A amostra utilizada para este artigo foi o Corpus Rio Acadêmico Escolar, composto por redações de candidatos que participaram das últimas edições do Vestibular da Universidade Federal do Rio de Janeiro, entre os anos de 2009 e 2012. É importante frisar que a escolha por esse corpus se deu pelo fato de as redações do ENEM não serem divulgadas pelas bancas examinadoras de modo que pudéssemos tomá-las como objeto de análise.

Para a composição do corpus, as redações foram selecionadas Adequação lexical como demonstrativo de competência comunicativa escrita no gênero redação aleatoriamente e, posteriormente, foram agrupadas de acordo com um dos critérios do processo de correção. 0 critério adotado foi o conceito atribuído à competência "Norma", de modo que o candidato poderia receber 0,50pto, 1,00 pto, 1,50 pto ou 2,00 pts. Para o exame das redações neste artigo, escolheu-se uma redação de cada conceito do ano de 2009.

A competência "Norma" leva em consideração a escolha de registro da língua, isto é, avalia-se o emprego da Norma culta escrita pelo candidato, desde as escolhas lexicais até o emprego de recursos estruturais mais elaborados para a tipologia argumentativa do gênero exigido no exame. No Vestibular, o candidato concluinte do Ensino Médio deve mostrar à banca examinadora que ele consegue dominar a modalidade formal da Língua Portuguesa ao elaborar um texto, já que o exame está enquadrado em uma situação de comunicação bastante formal. A predominante utilização de elementos provenientes da oralidade e/ou coloquialidade, portanto, acabam penalizando o candidato, pois são elementos inadequados à variedade exigida.

Em relação ao gênero, o participante do exame elabora um texto com o objetivo de demonstrar domínio adequado da modalidade escrita da língua portuguesa, em sua variedade culta, ou seja, ele escreve com a finalidade de ser avaliado quanto aos seus conhecimentos/capacidade de escrita para ter acesso a uma vaga no curso superior, por meio de um texto em prosa, paragrafado, com no máximo 30 linhas e contendo título, introdução, desenvolvimento e conclusão. Esse texto deve ter uma estrutura argumentativa, então, o candidato deve avaliar aspectos relacionados a uma temática e sustentar a sua tese por meio de argu- 


\section{Karen Pereira}

Fernandes de

Souza

Welton Pereira

e Silva mentos, isto é, o emprego de provas que a justifiquem e/ou apoiem. Com essa tipologia, busca-se convencer, influenciar, persuadir o leitor a aderir ao seu ponto de vista através de uma linguagem clara. Por ser um texto argumentativo, podem ser vistas marcas de pessoalidade no texto através da escolha lexical e das estruturas modalizadoras do discurso.

\section{Exame das redações e propostas de exercícios}

A seleção de um adequado repertório lexical, visando à demonstração da competência comunicativa através do uso da variedade culta da língua portuguesa, não é uma tarefa fácil. Objetivando demonstrar como os professores de português podem trabalhar a competência comunicativa, no que tange à adequação lexical, com seus alunos, fizemos, primeiramente, a análise de quatro redações de vestibular. Posteriormente, apresentamos as sugestões de exercício e correção.

Conforme comentado, o estudante, na vez de enunciador, precisa fazer uso de determinadas escolhas lexicais que estarão de acordo com o contrato instaurado a partir da proposta de redação apresentada. Na proposta do ano de 2009, o candidato deveria analisar aspectos relacionados ao tema "reflexões a respeito do olhar sobre a normalidade/anormalidade".

Para nos auxiliar no processo de análise das redações que apresentam problemas de adequação lexical, utilizaremos alguns dos fatores propostos por Pauliukonis (2007), professora da UFRJ preocupada com questões que relacionam a análise do discurso ao ensino de língua portuguesa, a saber: (a) adequação ao referente externo; (b) adequação ao contexto comunicativo; (c) adequação ao emissor e à situação interativa; (d) adequação ao registro linguístico escolhido; (e) adequação ao gênero textual; (f) adequação espacial; (g) adequação temporal; (h) adequação ao código escrito vigente.

Vejamos, por exemplo, o excerto abaixo, retirado de uma redação de vestibular:

(i) "Loucura ou Estrese

Sabemo que a mente é muito complicado como nosso corpo dependemos da nossa mente para pensar antes de agir poriso somos seres. Racionais Estamos sempre tem tando nos controlar para, não causar mar imperção tudo depende da nossa postura de que formar. Vamos lidar com os Problemas todos os dia. Temos. que aprender a se adapitar se não em louquecemos todos. Nós vivemos na coreria sem tempo para nada sempre es- 


\begin{abstract}
tressado, inrritado a Ponte de explodir o mundo parece que vai desabar todo. Parece não ter mais sentido bate um dezespero e a pessoa se pergunta será que estou ficando maluca e perde a razão." (Redação 0041 - Conceito: Norma = 0,50 pto)
\end{abstract}

Na redação $n^{0} 0041$, que obteve a nota 0,50 pto. para Norma linguística, há, realmente, muitos problemas de adequação lexical. Quanto à adequação ao código escrito vigente, há muitos problemas de grafia em vários vocábulos, tais como: <estrese>, <sabemo>, <poriso>, <tem tando>, <mar>, <imperção>, <adapitar>, <em louquecemos>, <dezespero> dentre outros. Muitos desses desvios deram-se pela influência da oralidade, como a epêntese do [i] em <adapitar>, o sândi externo em $<$ poriso>, a utilização do grafema <s> ao invés de <ss> para o fonema /s/ em <estrese $>$ e $<$ poriso $>$ e a utilização do grafema $<\mathrm{z}>$ ao invés de $<\mathrm{s}>$ intervocálico para representar o fonema /z/ em <dezespero>.

Há problemas também quanto à adequação ao emissor e à situação interativa, pois a banca examinadora, assumindo o papel de interlocutor, espera ler um texto com uma linguagem que reflita a situação interativa, criando, assim, uma imagem positiva do candidato. Entretanto, nos deparamos com os seguintes períodos nessa redação:

(1) Nós vivemos na coreria sem tempo para nada sempre estressado, inrritado a Ponte de explodir o mundo parece que vai desabar todo

(2) Parece não ter mais sentido bate um dezespero e a pessoa se pergunta será que estou ficando maluca e perde a razão

Ou seja, os trechos (1) e (2) quebram a imagem idealizada de um candidato preparado para o exame, pois essas estruturas muito informais não são esperadas neste gênero. Essas mesmas estruturas acabam ferindo, consequentemente, a adequação ao registro linguístico escolhido, pelo alto grau de coloquialidade utilizado na elaboração do texto. Além disso, os dois períodos supramencionados também não respeitam a adequação ao gênero textual, já que, além dos motivos já explanados, a estrutura utilizada como recurso tipológico, o descritivo-narrativo, não condiz com o recurso tipológico esperado no gênero redação de vestibular: o argumentativo. É importante ressaltar, contudo, que os demais tipos textuais podem vir a serviço do tipo argumentativo, pois este último deve ser o predominante neste gênero.

\section{Adequação \\ lexical como \\ demonstrativo \\ de competência \\ comunicativa \\ escrita no \\ gênero redação}




\section{Karen Pereira \\ Fernandes de \\ Souza \\ Welton Pereira \\ e Silva pende da postura de que formar", poderia ser mais bem empregado o enunciado "tudo depende da postura a ser tomada"; (c) em "se não em louquecemos todos", por "caso contrário, perdemos a razão"; (d) em "nós vivemos na correria", poderia ser empregado em seu lugar "a ocu- pação do dia a dia nos deixa sem tempo"; (e) em "a ponte de explodir", por "perdendo o controle"; (f) em "bate um dezespero", poderia ter sido usado "se instaura um pânico completo". \\ Analisemos a próxima redação:}

Como exemplos de seleção lexical inadequada, alguns vocábulos e/ou expressões poderiam ter sido empregados em lugar de outros. Vejamos alguns casos da redação 0041: (a) em "a mente é muito complicado", o termo "complicado" poderia ter sido substituído por "complexa", trazendo muito mais coerência e significado ao texto; (b) em "tudo de-

(ii) De médico e de louco, cada um tem um pouco

Na vida em uma sociedade, desde o nosso nascimento, até a nossa morte, somos submetidos a diversos costumes e regras, que são passados de geração a geração. Se nos negarmos a seguir esses costumes e essas regras, passaremos a sermos discriminados pelas pessoas que obedecem a essas regras e passaremos a sermos classificados como loucos.

Atualmente, somos submetidos a desempenhar várias tarefas, temos uma rotina muito estressante e corrida. Algumas pessoas não conseguem se adaptar a essa rotina e acabam sendo consideradas anormais.

A sociedade costuma considerar as pessoas que seguem seus costumes, regras e se adaptam a uma rotina "comum" a seus membros, como pessoas normais e uma pessoa que desempenha costumes diferentes ou não se adapta a uma rotina padrão aos membros dessa sociedade como pessoas anormais. Não concordo com esse modo de pensar de sociedade, para mim não existe pessoa que seja totalmente normal. Todas as pessoas passam por um momento de loucura na vida, pois felizes são as pessoas que vivem a vida sem seguir esses costumes e regras. (Redação 0024 - Conceito: Norma = 1,00 pto.)

Debruçando-nos sobre a redação que obteve a nota 1,00 pto. na competência relativa à Norma linguística, na redação noํ․ 0024, deste conjunto, 
deparamo-nos com uma definição vaga de alguns termos, o que também vai contra ao que Pauliukonis (2007) chamou de adequação ao referente externo:

(3) Se nos negarmos a seguir esses costumes e essas regras, passaremos a sermos discriminados pelas pessoas que obedecem a essas regras e passaremos a sermos classificados como loucos.

Notamos que o enunciador apresenta um argumento bem construído do ponto de vista estrutural. A partir do argumento inserido pela oração condicional, o estudante, na vez de enunciador, afirma que, ao negar-se a seguir certos costumes e regras sociais, o indivíduo é taxado como louco. $\mathrm{O}$ argumento falha do ponto de vista semântico, visto que os termos "regras" e "costumes" são vagos e a relação de causa e consequência, fraca. Quais regras e quais costumes devem ser seguidos para que alguém não seja classificado como louco? A loucura, nesse caso, poderia apresentar uma gradação semântica que varia do [- louco] ao [+ louco], passando por outros sentidos dados a essa palavra? A competência comunicativa, como visto anteriormente, diz respeito justamente à capacidade de os indivíduos comunicarem e serem compreendidos. Referir-se de maneira adequada a um referente externo bem definido é, portanto, fator que garante parte da coerência textual.

Com isso, notamos que a vagueza de certos itens lexicais, principalmente de nomes abstratos como os do exemplo acima, pode acarretar em uma falta de compreensão do enunciado, situação não desejável em um gênero textual que depende da boa comunicabilidade entre os sujeitos envolvidos na interação, visto que se trata de um concurso de vestibular.

Vimos, até aqui, alguns exemplos de inadequações lexicais que contribuíram para que as notas obtidas por esses estudantes no que concerne à utilização da modalidade culta da língua portuguesa fossem baixas. Agora, de modo a ilustrarmos como a boa escolha lexical pode auxiliar na obtenção de um bom rendimento nesses exames, apresentamos alguns excertos de redações que alcançaram boas avaliações: uma obteve 1,50 pto. e a outra, 2,00 pts. no critério "Norma". Vejamos a primeira:

(iii) A pseudo-evolução da mentalidade humana

Desde os primórdios, o mundo convive com a imensa diferença, entre pessoas, seres ou pensamentos. Porém, esse necessário hibridismo ao longo do tempo foi perdendo a importância. E 
Karen Pereira

Fernandes de

Souza

Welton Pereira

e Silva

196

é de extrema necessidade que mesmo tardiamente, as pessoas aprendam a aceitar que disto da realidade.

Nota-se que mesmo vivendo em um mundo tecnologicamente evolú́do, muitas pessoas ainda cultivam o preconceito. E o que deveria ser belo por ter diferenças, se torna estranho, esquisito ou fora dos padrões impostos pela sociedade. Não há como aceitar a incômoda presença da discriminação.

Observa-se que pessoas com problemas mentais são excluídas da sociedade. E estas, não deveriam ser tratadas como diferentes já que elas apenas vivem sem se preocupar com terceiras opiniões. Como a maioria dos indivíduos vivem em função do que os outros pensam, quem acaba não seguindo essa regra, é tido como diferente.

O que torna a natureza mais bela e exuberante, são suas diferenças de espécies, seres ou plantas. Ironia é ver que a diferença na natureza é incontestavelmente maravilhosa, mas esta entre os humanos é infinitamente contestada. Movimentos como o Nazismo, KuKluxKlan, Apartheid são exemplos de que as diferenças existem e não há como serem apagadas. Um exemplo disso é a raça ariana de Hitler que jamais existiu ou existirá.

Conclui-se que todas as formas de segregação, devem ser excluídas do mundo. Não adiante ter avanço tecnológico gigantesco, se a mentalidade ainda é um tanto quanto irracional. Brancos e negros, hetero ou homossexuais, devem viver de forma igualitária sem discriminações. Desta maneira, o crescimento na evolução jamais tenderá do lado positivo. (Redação 0003 - Conceito: Norma $=1,50$ pto)

Na redação № 0003 , que obteve a nota 1,50 pto., o participante fez uma introdução, desenvolveu o seu pensamento e fez um parágrafo de conclusão, mantendo-se dentro da adequação ao gênero textual. Essa redação é também um exemplo de adequação lexical no que concerne ao código escrito vigente, pois há raros vocábulos grafados erroneamente ou outros problemas gramaticais. Além disso, percebe-se que um grupo de vocábulos foi empregado com o intuito de agregar mais valor ao texto e todos os itens lexicais são pertencentes ao registro exigido no exame, tais como "pseudo-evolução", "hibridismo", "exuberante", “segregação", “incontestavelmente". 
Entretanto, há trechos com problemas de construção redacional, o que prejudica a compreensão do pensamento e, por isso, não se alcançou os 2,00 pts. nessa competência, tais como:

(4) a. as pessoas aprendam a aceitar que disto da realidade.

b. Desta maneira, o crescimento na evolução jamais tenderá do lado positivo.

Em (4a), há a presença da forma “disto", talvez remetendo a algo distante ou que distoa. Pelo contexto, não é possível compreender de forma inequívoca o sentido desse verbo grafado erroneamente, o que prejudica a compreensão textual. Há problemas em (4b), pois "crescimento" e "evolução" apresentam uma conotação positiva e o candidato Adequação lexical como demonstrativo de competência comunicativa escrita no gênero redação nega essa característica com os elementos “jamais tenderá”, provocando um paradoxo semântico. Há problemas também quanto à adequação ao registro linguístico escolhido, ao utilizar uma expressão corrente da linguagem cotidiana, uma expressão cristalizada, como em:

(5) um tanto quanto

Vejamos agora uma redação que tenha obtido 2,00 pts.:

(iv) A loucura e o progresso

Anos após anos de seleção natural conduziram a vida até os dias de hoje. Segundo Darwin, somente aos mais aptos é permitida a sobrevivência e a espécie humana adviria dos macacos. Tais afirmações, em sua época, foram sinônimos de loucura mas hoje dá-se a devida importância ao cientista. Pensar ou agir de modo anormal pode até ser considerado loucura mas foram loucos os maiores gênios da história.

Vive-se em uma natureza extremamente dinâmica, mudanças ocorrem a todo instante e se faz necessário responder a elas. A maioria da espécie humana age passivamente perante o processo, sequer percebe-o e continua a viver normalmente. Os ditos loucos são justamente os que propõem mudanças para o seu tempo, seriam anormais porque divergem da maioria. Por exemplo, Darwin, ao expor suas idéias, foi capaz de promover mudanças no modo de ver o mundo, necessários 
Karen Pereira

Fernandes de

Souza

Welton Pereira

e Silva

198 à evolução da espécie humana. No atual meio acadêmico, o indivíduo dito anormal seria aquele que ignora essas teorias e ideias, que em suas épocas eram classificadas como loucas e infundadas.

Ou seja, o conceito de que o que é normal ou anormal não é fixo, oscila com o tempo, por isso é muito difícil e perigoso conceituar algo ou alguém como louco. Pessoas como Darwin, Einstein, Mendel, Machado de Assis não são loucos por terem buscado mudanças, eles são verdadeiros gênios. Só com a loucura foram capazes de destacarem-se de um mundo de pessoas cada vez mais passivas e normais às mudanças que o tempo propõe.

Porém, é preciso lembrar que uma condição a genialidade é posicionar-se de forma anormal em relação aos outros, ser o louco, mas a recíproca nem sempre é verdadeira. Napoleão era um gênio em campo de batalha mas foi louco o suficiente de interferir na soberania das nações. Nesse caso, como em muitas outras, a loucura é evidenciada como algo ruim, pois foi incapaz de promover o progresso.

Portanto, a normalidade é o estado em que o homem perde a riqueza de sua imaginação, como disse Carlos Drummond. Ser o anormal é tentar promover as mudanças que a espécie humana deve passar para sobreviver. Só o tempo, entretanto, será capaz de selecionar os loucos, imortalizando alguns poucos como gênios. (Redação 0012 - Conceito: Norma = 2,00 pts)

Já na redação de número 0012, que alcançou a nota de 2,00 pontos no quesito Norma linguística, deparamo-nos com o seguinte excerto:

(6) Pensar ou agir de modo anormal pode até ser considerado loucura mas foram loucos os maiores gênios da história.

Observamos que o candidato definiu de forma adequada seu conceito de loucura, visto que o comportamento de pensar ou agir de modo anormal seria o que a definiria. É importante ressaltar que, diferentemente do que ocorreu nas redações anteriormente analisadas, o referente externo foi bem conceituado, visto que o candidato trouxe todo um contexto histórico de modo a ilustrar e exemplificar sua conceituação de "normalidade" e "loucura". Apesar disso, o próprio estu- 
dante, na vez de enunciador, deixa clara a fluidez semântica e discursiva dos termos "normal" e "anormal", demonstrando possuir um alto nível de educação formal:

(7) Ou seja, o conceito de que o que é normal ou anormal não é fixo, oscila com o tempo, por isso é muito difícil e perigoso conceituar algo ou alguém como louco.

Adequação
lexical como
demonstrativo
de competência
comunicativa
escrita no
gênero redação

pensamento crítico. Na redação acima, como podemos perceber, a escolha lexical de termos e expressões mais bem elaborados como "conceito", "oscila com o tempo", "condição de genialidade", "interferir na soberania das nações", "promover o progresso", por exemplo, contribuiu para que o candidato obtivesse uma alta classificação no que concerne à nota relativa ao uso da Norma linguística.

$\mathrm{Na}$ verdade, conforme vimos durante o decorrer deste trabalho, a escolha lexical, por si só, não produz tantos resultados favoráveis. A competência comunicativa do candidato deve ser demonstrada através da adequação lexical ao contexto de produção, à situação de comunicação, ao gênero textual. Ou seja, ao adequar a escrita (utilizando bem a norma culta e empregando o registro correto - no caso, o formal) no gênero "redação de vestibular" (situação específica de comunicação escrita escolar em que os estudantes são submetidos a treinar na escola), o candidato possui maiores chances de atingir uma boa nota no exame.

Cabe ao professor de língua portuguesa a tarefa de incutir nos alunos a importância de um bom uso da modalidade formal escrita do idioma, buscando refletir, com eles, acerca do que seria adequado ou inadequado a determinados contextos comunicativos, através de exercícios de variação linguística ao mesmo tempo em que se trabalha diferentes gêneros textuais, por exemplo. A ampliação do repertório lexical, contudo, não depende apenas do professor, afinal, é fator crucial para a amplificação do vocabulário a prática cotidiana de leitura e consultas a dicionários e enciclopédias (físicas ou digitais). 


\begin{abstract}
Karen Pereira
Fernandes de

Souza

Welton Pereira

e Silva

200 que o aluno tem competência comunicativa e que conhece as exigências de registro do contrato de comunicação. Como já disse Evanildo Bechara, "o falante deve ser poliglota em sua própria língua", portanto, é extremamente importante que o professor trabalhe gêneros variados com seus alunos, pois cada gênero exigirá um registro mais ou menos formal e, com isso, trabalham-se a variação linguística e adequação vocabular.

Por essas razões, apresentamos algumas sugestões de exercícios práticos que visam a melhorar a percepção e a reflexão do aluno em relação à importância da adequação vocabular de acordo com o registro e a norma solicitados na interação comunicativa. Eles podem ser aplicados com alunos de $2^{\circ}$ e $3^{\circ}$ anos do Ensino Médio. A escolha desses se justifica pelo fato de já estarem mais amadurecidos para reflexões no uso/produção da língua portuguesa; além disso, seriam os dois anos mais próximos do exame de Vestibular e/ou ENEM.
\end{abstract}

Além disso, a não observação da Norma culta escrita, no que diz respeito aos níveis de formalidade/informalidade, traz maior penalidade ao candidato, pois saber se expressar de maneira formal durante uma situação de comunicação, seja texto seja fala, e saber se expressar de maneira informal em uma outra interação comunicativa significa

\subsection{Propostas de exercícios}

1. Com o auxílio de um dicionário, procure o significado do vocábulo "XXX". Em seguida, elabore um parágrafo de 10 linhas (com introdução, desenvolvimento e conclusão) na modalidade culta da língua sobre o tema "XXX" de modo que essa palavra cujo significado novo foi aprendido esteja presente e bem articulada ao contexto criado.

2. Substitua as palavras e/ou expressões sublinhadas de sentido negativo e/ou de significado vago por outras de sentido mais neutro/positivo e/ou específico:

a. Os grevistas decidiram continuar com a algazarra na frente do portão.

b. Pedro tem uma venda e é dono de um barraco no mesmo morro. c. O governo precisa fazer algo a respeito dos problemas ocasionados pelas chuvas.

2 A ser indicado pelo professor de acordo com algum texto trabalhado em interpretação textual/ gramática durante a aula, por exemplo. Além do enriquecimento do léxico e da produção textual, essa tarefa visa uma aproximação mais íntima entre o aluno e o dicionário. 
d. Pedro estava muito cheio, porque devorou muitas pizzas no rodízio.

e. Corremos até o hospital porque recebemos uma notícia ruim sobre a vida da minha tia internada, mas chegando lá, ela já tinha esticado as canelas.

f. Várias coisas foram ditas pelo advogado de defesa.

Adequação

lexical como

demonstrativo

3. A partir da leitura do diálogo abaixo, reescreva-o de modo que o novo de competência texto fique o mais específico que puder. 0 registro informal deve ser mantido:

- Mãe, acabei de passar lá embaixo, quando cheguei da rua, e o rapaz que está por lá agora acabou de me entregar isso aqui e me pediu que eu te entregasse... Isso é seu? Por que ele me entregou isso? comunicativa escrita no gênero redação

- Ah! Sabe o que é... Eu vi que tinha pão velho aqui e resolvi fazer umas torradas para mim de tarde. Mas foram muitas e sobraram. Aí, eu interfonei para ele e perguntei se ele sentia vontade de comer alguma coisa. Então eu passei um quentinho na máquina e dei para ele isso aí com as torradas.

4. Após a leitura das situações e das falas do âncora de um telejornal e do político a seguir, reescreva o discurso dos personagens de modo que os textos fiquem adequados quanto ao registro da situação comunicativa, fazendo as adequações lexicais que se fizerem necessárias:

Situação A: Um âncora de um telejornal renomado, em horário nobre e em rede nacional, noticia o seguinte: "Os favelados de um morro no Rio foram pegos de surpresa com a tamanha avalanche de lama e terra que desceu morro abaixo durante a chuvarada desta noite."

Situação B: Um candidato a Prefeito se dirige a uma comunidade carente em comício e diz o seguinte: "Tenciono encerrar para sempre a dificuldade de esgotamento básico em vossos logradouros a fim de erradicar doenças e locais insalubres, beneficiando a todos os habitantes desta região!"

5. A partir do exercício anterior, explique, com suas palavras, por que as falas dos personagens não estavam adequadas aos contextos comunicativos apresentados? 


\subsection{Sugestões de gabarito}

1. Livre.

2. a. Os trabalhadores/sindicalistas decidiram continuar com $\underline{0}$ protesto/a manifestação na frente do portão. / b. Pedro é comerciante

Karen Pereira

Fernandes de

Souza

Welton Pereira

e Silva

202 e é proprietário de uma casa/residência na mesma comunidade. / c. 0 governo precisa criar políticas públicas a respeito dos problemas ocasionados pelas chuvas. / d. Pedro sentia-se muito satisfeito/saciado, porque comeu muitas pizzas no rodízio. / e. Dirigimo-nos até o hospital porque recebemos uma informação sobre o estado de saúde da minha tia internada, mas chegando lá, ela já tinha falecido. / f. Vários argumentos foram proferidos pelo advogado de defesa.

3. - Mãe, acabei de passar pela portaria/saguão do prédio, quando cheguei da rua, e o funcionário/porteiro que está trabalhando agora acabou de me entregar essa jarra/copo/garrafa térmica e me pediu que eu te entregasse... Ela/ele é sua/seu? Por que ele me entregou isso?

- Ah! Sabe o que é... Eu vi que tinha pão velho na cozinha e resolvi preparar umas torradas para mim de tarde. Mas foram muitas e sobraram. Aí, eu interfonei para o funcionário/porteiro e perguntei se ele sentia vontade de lanchar. Então eu passei um café quentinho na máquina e entreguei para ele essa jarra/copo/garrafa térmica com as torradas.

4. Situação A: "Os moradores de uma comunidade do Rio foram surpreendidos com a enxurrada de lama e terra que ocorreu durante o temporal desta noite." / Situação B: "Pretendo resolver de uma vez por todas o problema do saneamento básico para pôr fim nas doenças e locais sujos de esgoto a céu aberto para todos os moradores desta região."

5. Situação A: pelo fato de ser um jornal televisionado, o âncora deveria fazer uso de um registro mais formal, não lançando mão de itens lexicais com sentido tão negativo e estigmatizado, como "favelado". / Situação B: por ser um comício destinado a uma comunidade carente, a escolha lexical de termos pouco usuais se mostra inadequada, já que compromete o entendimento do que foi dito pelo candidato aos eleitores. 


\section{Considerações Finais}

A adequação lexical é preponderante para o desenvolvimento de uma interação que cumpra as finalidades desejadas pelos parceiros envolvidos na troca comunicativa. Desse modo, faz parte da competência comunicativa do falante a consciência acerca dos riscos e recompensas gerados a partir de uma boa escolha vocabular.

Como certas escolhas lexicais carregam julgamentos de valor e acabam por demonstrar o ponto de vista do enunciador em relação a um determinado assunto, essa noção deve ser ampliada para toda e qualquer situação de comunicação da qual o aluno venha participar. No entanto, nosso foco se deu sobre as redações de vestibular, visto essas serem um gênero cuja finalidade é avaliar a competência escrita do participante e, por consequência, promover ou não a entrada do aluno no nível superior de ensino.

Adequação

lexical como

demonstrativo de competência comunicativa escrita no gênero redação

Como vimos no presente trabalho, é de suma importância que o professor de língua portuguesa suscite, em seus alunos, a reflexão a respeito da necessidade de apresentarem um vasto repertório vocabular de modo a mais bem se expressarem. A consulta a bons dicionários faz parte do aprendizado e não deve ser uma prática esquecida, abandonada, como têm feito as escolas atualmente. Tal prática em sala de aula auxilia o nível ortográfico do aluno e também tem a sua importância no exame, pois mostra que o candidato possui bom domínio da modalidade culta escrita da Língua Portuguesa.

Outro ponto importante sobre a Norma exigida no exame de seleção é a utilização de expressões cristalizadas que fazem parte da norma de uso popular (correntes no dia a dia) e o emprego de vocábulos vagos sem um referente externo bem delimitado. Pontuando esses recursos como desvios e/ou inadequação lexical, como observamos, eles acabam por gerar problemas de cunho interpretativo que favorecem a obtenção de uma nota baixa quanto ao critério Norma nas redações de vestibular.

O presente trabalho procurou demonstrar a forma como a adequação lexical, considerando fatores textuais-discursivos, é de suma importância no momento da escrita em um concurso ou vestibular. Munidos dessa noção, tanto os professores de língua materna quanto os estudantes poderão buscar formas de aplicar melhor o uso da língua em diferentes momentos interacionais. Além disso, apresentamos alguns exercícios práticos que farão com que o aluno reflita sobre a importância da adequação lexical como demonstrativo de sua competência comunicativa ao ter sua redação avaliada no exame do Enem e/ou Vestibular. 


\section{REFERÊNCIAS}

BRASIL, Secretaria de Educação Fundamental. Parâmetros curriculares nacionais: terceiro e quarto ciclos do ensino fundamental: Língua Portuguesa. Brasília: MEC/SEF, 1998. 106 p.

Karen Pereira

Fernandes de

Souza

Welton Pereira

e Silva

204
CÂMARA JR, Joaquim Mattoso. Estrutura da língua portuguesa. Petrópolis: Vozes, 1970. $114 \mathrm{p}$.

CHARAUDEAU, Patrick. Análise do discurso: controvérsias e perspectivas. In: MARI, H. et alii (org.). Fundamentos e dimensões da Análise do Discurso. Belo Horizonte: Fale/NAD, 1999.

COSERIU, Eugenio. Sistema, norma e fala. In: Teoria da linguagem e linguística geral. Rio de Janeiro: Presença, 1987. p. 13-85.

FARACO, Carlos Alberto. Norma culta brasileira: desatando alguns nós. São Paulo: Parábola, 2008.

MARCUSCHI, Luiz Antônio. A. Produção textual, análise de gêneros e compreensão. $1^{\mathrm{a}}$ ed. São Paulo: Parábola, 2017.

PAULIUKONIS, Maria Aparecida Lino. Ensino do léxico: seleção e adequação ao contexto. In: PAULIUKONIS, Maria Aparecida Lino; GAVAZZI, Sigrid (orgs.). Da língua ao discurso: reflexões para o ensino. Rio de Janeiro: Lucerna, 2007. p. 103-128.

POSSENTI, Sírio. Teoria do discurso: um caso de múltiplas rupturas. In: MUSSALIM, Fernanda; BENTES, Anna Christina. Introdução à linguística. Fundamentos Epistemológicos. Volume 3. São Paulo: Cortez, 2004.

SIMÕES, Darcilia; REI, Claudio Artur O. Competência expressional e léxico: uma proposta para o ensino. In: Aulas de português: o léxico em foco. Rio de Janeiro: Dialogartes, 2015.

TRAVAGLIA, Luiz Carlos. Gramática e interação: uma proposta para o ensino de gramática no $1^{\circ}$ e $2^{\circ}$ graus. São Paulo: Cortez, 1997. 
VIEIRA, Silvia Rodrigues; COELHO, Adriana Rodrigues Lopes (orgs.). Corpus Rio Acadêmico Escolar. Rio de Janeiro: Faculdade de Letras/ UFRJ, 2010.

\author{
Adequação \\ lexical como \\ demonstrativo \\ de competência \\ comunicativa \\ escrita no \\ gênero redação
}


